\title{
A study on heat storage sizing and flow control for a domestic scale solar- powered organic Rankine cycle-vapour compression refrigeration system
}

\author{
Cagri Kutlu ${ }^{1}$, Mehmet Tahir Erdinc ${ }^{2}$, Jing $\mathrm{Li}^{* 1,3}$, Yubo Wang ${ }^{4}$, Yuehong Su ${ }^{* * 1}$ \\ ${ }^{I}$ Department of Architecture and Built Environment, University of Nottingham, University Park, Nottingham \\ $N G 72 R D, U K$ \\ ${ }^{2}$ Department of Mechanical Engineering, Osmaniye Korkut Ata University, 80000 Osmaniye, Turkey \\ ${ }^{3}$ Department of Thermal Science and Energy Engineering, University of Science and Technology of China, 96 \\ Jinzhai Road, Hefei, 230026, China \\ ${ }^{4}$ School of Economics and Management, Hubei University of Technology, Wuhan, Hubei, 430068, China
}

This paper presents the off-design modelling of a domestic scale solar organic Rankine cycle (ORC) and vapour compression cycle (VCC) in a coupled operation in different operating modes by using evacuated flat plate (EFP) collectors. Thermodynamic and parametric studies of such coupled system in literature usually assume that the isentropic efficiencies of expander and compressor and the heat exchanger pinch temperature differences are constant. Moreover, studies for directly coupling the ORC-VCC system with solar collectors are somewhat rare. Transient performance of the solar ORCVCC considering the off-design behaviour of the system components needs to be investigated. A simulation for a period of $24 \mathrm{hrs}$ is conducted by considering the electricity and cooling demand of a $60 \mathrm{~m}^{2}$ office building during a typical day in July for Istanbul. The effect of heat storage capacity on meeting the demand is investigated for a given area of EFP collectors. Moreover, the water flow rate to the boiler is controlled periodically to provide the demanded electricity and cooling. The required EFP collector area and heat storage unit volume have been determined to be $80 \mathrm{~m}^{2}$ and $9.4 \mathrm{~m}^{3}$, respectively. For these design parameters, $25.6 \mathrm{kWh}$ cooling and $18.76 \mathrm{kWh}$ electricity can be generated during a typical day in July. Finally, a simulation is given for such design on a sunny winter day in February, $5.5 \mathrm{kWh}$ electricity and $104 \mathrm{kWh}$ heat can be produced.

Keywords: Solar Organic Rankine Cycle (ORC), vapour compression cycle (VCC), heat storage unit, off-design, control of flow rate

\footnotetext{
*First corresponding author. Jing Li, jing.li@ hull.ac.uk

** Second corresponding author. Yuehong Su, yuehong.su@nottingham.ac.uk
} 
A Area, $\mathrm{m}^{2}$

$c_{1} \quad$ Heat loss term, $\mathrm{W} \mathrm{m}^{-2} \mathrm{~K}^{-1}$

$c_{2} \quad$ Heat loss term, $\mathrm{W} \mathrm{m}^{-2} \mathrm{~K}^{-2}$

$c_{p} \quad$ Specific heat, $\mathrm{J} \mathrm{kg}^{-1} \mathrm{~K}^{-1}$

$G \quad$ Solar irradiance, $\mathrm{W} \mathrm{m}^{-2}$

$h \quad$ Specific enthalpy, $\mathrm{J} / \mathrm{kg}$

$h_{h} \quad$ Heat transfer coefficient, $\mathrm{W} \mathrm{m}^{-2} \mathrm{~K}^{-1}$

$\mathrm{k}$ Thermal conductivity, $\mathrm{W} \mathrm{m}^{-1} \mathrm{~K}^{-1}$

$K_{\theta} \quad$ Incident angle modifier

$\dot{m} \quad$ Mass flow rate, $\mathrm{kg} \mathrm{s}^{-1}$

M Mass, $\mathrm{kg}$

N Rotation speed, RPM

$\mathrm{Nu} \quad$ Nusselt number

$\dot{Q} \quad$ Heat rate, $\mathrm{W}$

$\mathrm{P} \quad$ Pressure, $\mathrm{Pa}$

Pr Prandtl number

Re Reynolds number

$\bar{T} \quad$ Mean temperature, ${ }^{\circ} \mathrm{C}$

$T \quad$ Temperature, ${ }^{\circ} \mathrm{C}$

$U \quad$ Overall heat transfer coefficient, $\mathrm{W} \mathrm{m}^{-2} \mathrm{~K}^{-1}$

$v \quad$ Specific volume, $\mathrm{m}^{3} / \mathrm{kg}$

$\dot{W} \quad$ Power, $\mathrm{W}$

X` Vapour quality

$X_{p} \quad$ Pump capacity fraction

\section{Greek letters}

$\begin{array}{ll}\eta & \text { Efficiency } \\ \rho & \text { Density, } \mathrm{kg} \mathrm{m}^{-3}\end{array}$

\section{Subscripts}

ad Adapted

am Ambient

b boiling

col Collector

con Condenser

comp compressor

$\mathrm{cw}$ Water in collector

eva Evaporator

ex Exhaust

exp Expander

i Isentropic

in Internal expansion

$l \quad$ liquid

leak Leakage

mec Mechanical

$r \quad$ Refrigerant

$r c \quad$ Refrigerant in cooling cycle

su Supply

sw Swept volume

st Storage

st,N Last node

$v \quad$ Vapour

$w \quad$ Water

wo Water out from boiler

$t \quad$ Tank

tur Turbine 


\section{Introduction}

Electricity is becoming an increasingly crucial need for people, with electricity demand increasing day by day. Such electricity consumption has been triggered by a higher dependency and usage of electrical appliances in every dwelling, as well as the desire for improved living standards and more comfortable social environments using refrigeration systems. It is reported that in some cities, up to $50 \%$ of the supplied electricity during summer months is consumed by air conditioning applications [1]. Whilst this demand is being met by the suppliers, this will, however, cause further environmental concerns about fossil fuels' damage on environment and future shortage. Furthermore, indoor environments in these cities need to be heated for some periods during the year. Thus, fossil fuels are still used even if not by electrical heaters. Renewable energy is encouraged by governments and societies, therefore the use of renewable sources such as solar, geothermal and wind energy [2], [3],[4] to produce electricity offers great opportunity for reducing the fossil fuels consumption level.

Since solar thermal systems have a great potential to produce combined electricity, heating and cooling, solar thermal energy-related systems have been developed exponentially over the last decades. Solar trigeneration systems commonly have an absorption refrigeration cycle to obtain cooling from the collected solar heat [5], [6], [7]. To meet both electricity and cooling demand, a combination of a solar organic Rankine cycle (ORC) with a vapour compression cycle (VCC) can also be applicable. In this kind of systems, the expander shaft of the ORC and the compressor shaft of the VCC are coupled directly to reduce two-way energy conversion losses. Different from the absorption and desiccant refrigeration systems, the ORC-VCC system is flexible by the way of outputting power when there is no need to cooling. In a hot summer, most of solar heat can be used for to refrigeration, while less heat is used for cooling in spring and fall. When there is no need for cooling, the all available thermal energy can be converted to electricity and sent to the grid [8]. The present configuration has been investigated by a number of researchers but with some assumptions.

Some studies focused on a more effective system design by adding internal heat exchangers and recuperators [8],[9], however, most studies were conducted to find the best working fluid through first and second law analysis [10], [11], [12], [13], [14], [15]. These kinds of parametric studies show performance of the system under a wide range of working conditions. However, during investigation of one parameter's influence on the system, all other parameters were held constant as if all components were operating according to design conditions'. Thus, isentropic efficiencies and heat exchanger pinch temperature differences were assumed as constant in the literature, despite it being known that system performance is related to operating conditions. To overcome this issue, system components need to be modelled and simulated in off-design operation.

The ORC-VCC system has a great capacity for using waste heat and solar source, however, studies for directly coupled this with a solar source are somewhat rare. A summary of the previous studies on 
ORC-VCC systems is given in Table 1. Zheng et al. [16] investigated the performance of a solar Rankine cycle powered VCC by using zeotropic mixtures, although solar radiation was taken as constant in order to assess the performance of different refrigerants. The present study shows the transient performance of the ORC-VCC system using real solar radiation data. As is the nature of solar energy, the required solar energy is not available 24 hours to operate ORC-VCC, thus, when solar radiation is not available to drive the system, solar heat must be stored during the daytime. Therefore, a water storage tank is incorporated into system as a heat storage unit. Finally, a case study on meeting the cooling and electricity demand during a day, is conducted. To match the demand, a control strategy is adapted and its affect is investigated. Moreover, the system's performance in a sunny winter day operation in February is simulated to observe CHP mode performance. Thus, the cost effective performance of the system by operating in different modes can be clearly presented.

In summary, this study differs from the literature with a point of using transient analysis of the components and using solar energy as a heat source with integrating a water storage unit. The effect of the water storage capacity and control strategies on meeting the combined cooling and electricity demand are investigated. Moreover, the system configuration allows to operate even in winter by changing the operation mode from ORC-cooling to ORC-heating.

Table 1. Summary of the previous studies on ORC-VCC systems

\begin{tabular}{|c|c|c|c|c|}
\hline Reference & Working fluid & $\eta_{\text {tur-exp }}$ & Heat Source & Notes \\
\hline [8] & R245fa & 0.75 & $\begin{array}{l}\text { N.A Boiler } \\
\text { temp. } 190^{\circ} \mathrm{C}\end{array}$ & Many modifications \\
\hline [9] & R22-R134a-R290 & 0.8 & $\begin{array}{l}\text { Flue gas (input } \\
180-200^{\circ} \mathrm{C} \\
\text { output } 100^{\circ} \mathrm{C} \text { ) }\end{array}$ & $\begin{array}{l}\text { Compared basic and regenerative } \\
\text { cycles with exergy analysis. }\end{array}$ \\
\hline$[10]$ & $\begin{array}{l}\text { R290-R600-R600a- } \\
\text { R1270 }\end{array}$ & $0.8(0.6-0.9)$ & $\begin{array}{l}\text { N.A (Boiler exit } \\
\left.60-90^{\circ} \mathrm{C}\right)\end{array}$ & Parametric study \\
\hline [11] & $\begin{array}{l}\text { R143a-R22-R134a- } \\
\text { R152a-propane- } \\
\text { ammonia-isobutane- } \\
\text { butane }\end{array}$ & 0.8 & $\begin{array}{l}\text { Source } \\
\text { temperature } \\
\text { fixed at } 150^{\circ} \mathrm{C} \\
\text { air. }\end{array}$ & $\begin{array}{l}\text { NTU, size parameter and isentropic } \\
\text { volumetric flow ratio analysis and } \\
\text { exergy }\end{array}$ \\
\hline [12] & $\begin{array}{l}\text { R134a-R1234yf- } \\
\text { R1234ze(E) }\end{array}$ & 0.8 & $\begin{array}{l}\text { N.A Boiler } \\
\text { exit }\left(102^{\circ} \mathrm{C}-\right. \\
\left.152^{\circ} \mathrm{C}\right)\end{array}$ & $\begin{array}{l}\text { Separate system, parametric study } \\
\text { and feasibility were conducted }\end{array}$ \\
\hline [13] & $\begin{array}{l}\text { R123-R600-R245fa- } \\
\text { R141b-R600a }\end{array}$ & 0.75 & $\begin{array}{l}\text { N.A (Boiler } \\
\text { temp. } 90^{\circ} \mathrm{C}- \\
120^{\circ} \mathrm{C} \text { ) }\end{array}$ & Exergy and parametric study \\
\hline [14] & $\begin{array}{l}\text { R245fa,R123,R134a, } \\
\text { R1234yf, R1234ze } \\
\text { (E) }\end{array}$ & 0.8 & $\begin{array}{l}\text { Hot water at } \\
100^{\circ} \mathrm{C}\end{array}$ & $\begin{array}{l}\text { Separate system, exergy analysis. } \\
\text { Pinch point heat exchanger } \\
\text { analysis. }\end{array}$ \\
\hline
\end{tabular}




\begin{tabular}{|c|c|c|c|c|}
\hline$[15]$ & $\begin{array}{l}\text { R1270-R290-RC318- } \\
\text { R236fa-R600a- } \\
\text { R236ea- R600- } \\
\text { R245fa-R1234yf- } \\
\text { R1234ze(E) }\end{array}$ & $0.8(0.6-0.9)$ & $\begin{array}{l}\text { N.A(Boiler } \\
\text { temp } 60^{\circ} \mathrm{C} \quad- \\
\left.90^{\circ} \mathrm{C}\right)\end{array}$ & Parametric study \\
\hline$[16]$ & $\begin{array}{l}\text { Various pure fluids } \\
\text { and zeotropic } \\
\text { mixtures }\end{array}$ & $0.85(0.85-1)$ & $\begin{array}{l}\text { Solar (expander } \\
\text { inlet } 60^{\circ} \mathrm{C} \quad- \\
120^{\circ} \mathrm{C} \text { ) }\end{array}$ & Zeotropic mixtures investigated \\
\hline [17] & $\begin{array}{c}\text { R245fa (cooling } \\
\text { R134a) }\end{array}$ & 0.75 & $\begin{array}{l}\text { Engine } \\
\text { gas } \\
\text { (Boiler } \\
\left.190^{\circ} \mathrm{C}\right)\end{array}$ & $\begin{array}{l}\text { Separate system, in experiment, } \\
\text { flow rate was changed and } \eta_{\exp } \\
\text { varied. }\end{array}$ \\
\hline$[18]$ & R134a- R245fa & $0.9-0.8-0.7$ & $\begin{array}{l}\text { Bus engine } \\
\text { exhaust gas-oil } \\
\left(310-360^{\circ} \mathrm{C}\right)\end{array}$ & Transcritical cycle \\
\hline
\end{tabular}

\section{System description}

The proposed system consists of four sub-systems, namely, an array of solar field, a heat storage unit, an ORC block and the VCC. The ORC comprises four main units, specifically, pump, boiler, expander and condenser. The refrigeration system also has four main units, namely, compressor, condenser, expansion valve and evaporator. Although the present study focuses on summer application to produce both power and cooling, the components were selected to allow for operation in winter as well for production of electricity and heating. In order to operate the system in all seasons, some operation modes need to be determined and these are given below:

Mode 1- ORC-Cooling: this operation mode covers the main part of the paper. Original ORC-VCC operation is required during the summer period to generate enough power to produce cooling at the same time. Fig.1a shows the schematic view of the system. Blue dashed lines show inactivity in this mode; a detailed explanation of the operation will be given.

Mode 2- ORC-Heating: this mode can be used when heating is demanded by residents. If sufficient heat is stored in the tank to drive the ORC which is directly related with the solar radiation profile in that day, the system can operate the ORC cycle and condensing heat from the ORC can be used for heating the property. As shown in Fig.1b, the evaporator of the refrigeration system turns into an ORC condenser and blue dashed lines are inactivated.

Mode 3- Heating: solar energy may be unavailable or fairly weak on some days in winter. Thus, water temperature in the tank cannot be increased to a high enough level. On these days the system is unable to produce electricity from the ORC. However, heating is still demanded by the residents. Lower temperature water in the tank can therefore be used for heating, a process which is commonly studied, thus it will not be simulated in this study. 
Since it is assumed that the system will operate smoothly in the three modes, solar collectors, heat storage medium and expander were carefully selected on the following basis:

Evacuated flat plate (EFP) collectors were chosen as solar collectors given that they have advantages over other types. They do not need a sun tracking system and they perform reasonably well even under low radiation and low ambient temperature conditions when compared to conventional flat plate collectors, thus there is a potential for use in winter [19]. Despite the higher cost, their ability to operate during cold periods shows that EFP collectors are a good candidate for domestic trigeneration systems. Water was chosen as the working fluid in the solar cycle. Given the temperature range of the solar circuit which is below $150{ }^{\circ} \mathrm{C}$, this also makes water a suitable working fluid which can be directly coupled with a pressurised water tank. A water tank is used as a heat storage unit to provide heat for the ORC, thus making a stable power generation for avoiding variation due to changing solar irradiance. Moreover, it allows the operation of the ORC when solar radiation is insufficient or unavailable. EFP collectors are used for heating water which comes from the bottom of the tank $\left(\mathrm{T}_{\mathrm{st} 10}\right)$ and is then discharged into the top of the water tank at a higher temperature $\left(\mathrm{T}_{\text {col }}\right)$.

High temperature water in the tank is used as a heat source for the ORC at $\left(\mathrm{T}_{\mathrm{st} 1}\right)$. A concentric tube heat exchanger is adopted as a boiler for the ORC block and high-pressure working fluid is evaporated in this boiler. After evaporating (3), high pressure and high temperature working fluid enters into the expander. As an expander device, a scroll type expander was selected as these are well adapted to small-scale Rankine cycle applications and further, offer the advantages of low rotational speeds, reliability and ability to operate without significant performance reduction in different operating conditions [20]. Regarding the working fluid selection, Saleh [15] reported that R600 and R245fa achieved the best performance among other candidates in his parametric analysis. Therefore, as seen in Table 1, the commonly preferred working fluid R245fa was chosen to use in this study.

After the expander, the operating mode determines the path of the working fluid. For ORC-cooling mode, the condenser is in common use by both the ORC and VCC systems, which lead the same refrigerant circulating in both cycles, one comes from the expander (4), the other from the compressor (r4), thereafter, the two are mixed in the auxiliary component mixer before entering the condenser. Later, the refrigerant is separated through the two cycles after condensing. One path goes into the pump (1) and leaves it with higher pressure (2). The other path is for the refrigeration cycle (r1). Working fluid pressure and temperature is decreased by the expansion valve (r2) then via the evaporator, the refrigerant is evaporated and provides cooling. After the evaporator (r3), working fluid pressure and temperature is increased by the compressor.

For the ORC-heating mode, the compressor and expansion valve are not in use. The working fluid directly enters the new condenser which was the indoor air unit evaporator in ORC-cooling mode after the expander. While the fluid is condensing, taken heat is used for heating the room. 

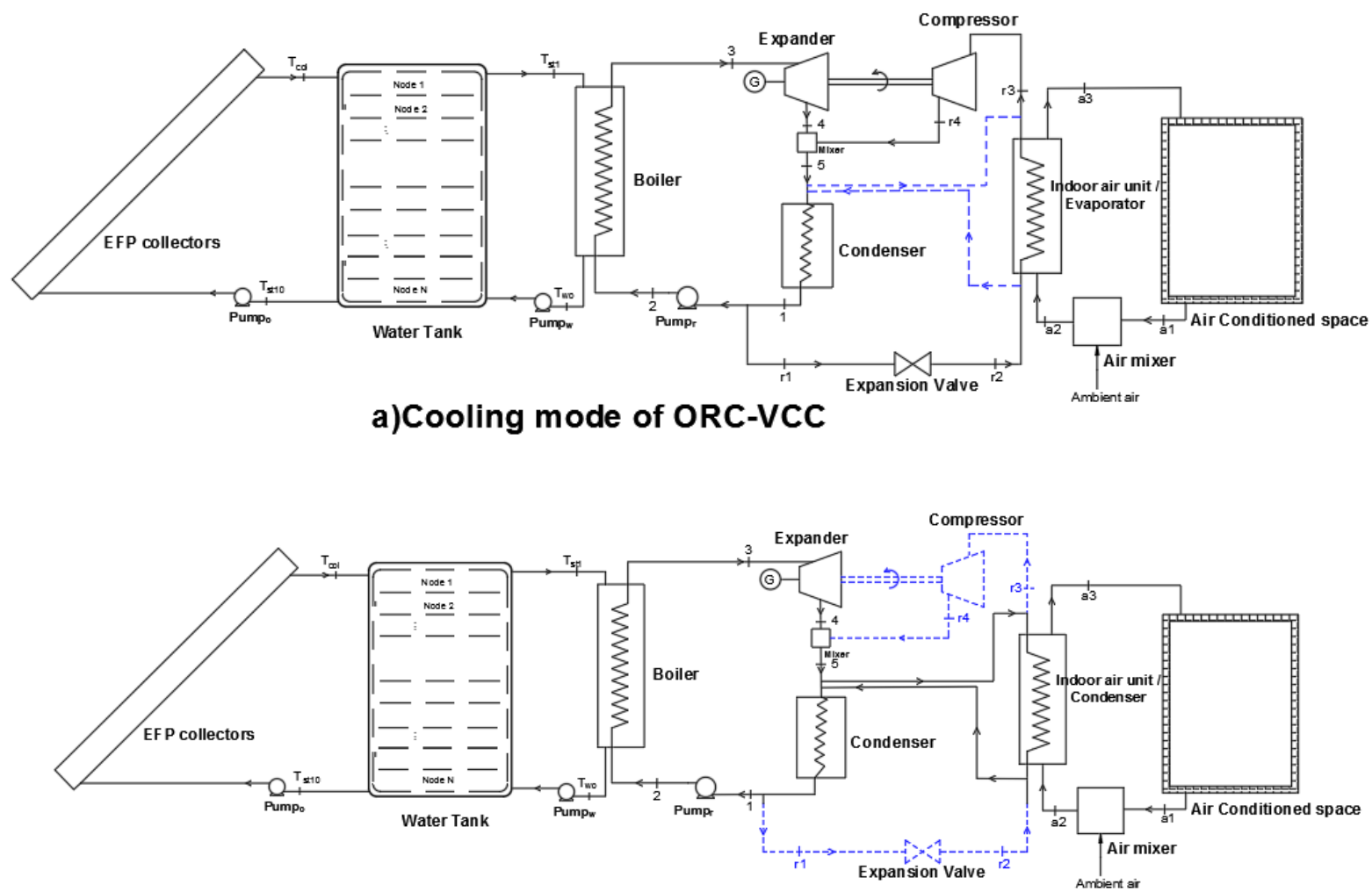

b)Heating mode of ORC-VCC

Fig.1. Schematic views of heating and cooling modes of ORC-VCC

For the air cooling section of the ORC-VCC system, the exhaust air from the conditioned space is mixed with ambient fresh air. This mixture is cooled at the evaporator and supplied to the conditioned space. The cooling load which impacts directly on the operation of the compressor, is calculated by using the software EnergyPlus [21] for the given data of Istanbul. A $60 \mathrm{~m}^{2}$ office room was assumed for the case study and Fig.2 gives the cooling and electricity demands for the selected room during a typical day in July. To conduct the analysis, some assumptions were made:

- For the cooling mode of the ORC-VCC system, the difference between the condensation temperature and the ambient air temperature was considered to be $10^{\circ} \mathrm{C}$ [22], [23]. This value is practically recommended for obtaining appropriate cost of heat exchanger [24].

- For the cooling mode of the ORC-VCC system, the evaporation temperature of the VCC is fixed at $5^{\circ} \mathrm{C}$ with assumption of no superheating. The conditioned space has a temperature of $24^{\circ} \mathrm{C}$ and $50 \%$ relative humidity [14].

- For the heating mode of the ORC-VCC system, the VCC is not in use. The indoor air unit acts as the condenser of the ORC system and its condensation temperature was considered as $38^{\circ} \mathrm{C}$ [24]. 
- The mechanical efficiency of the compressor $\eta_{m e c}$ changes between $0.95-1$ and it can be assumed as 0.95 [18].

According to the given assumptions, the corresponding P-h diagram of the ORC-VCC system for boiling temperature of $90^{\circ} \mathrm{C}$ is given in Fig. 3 .

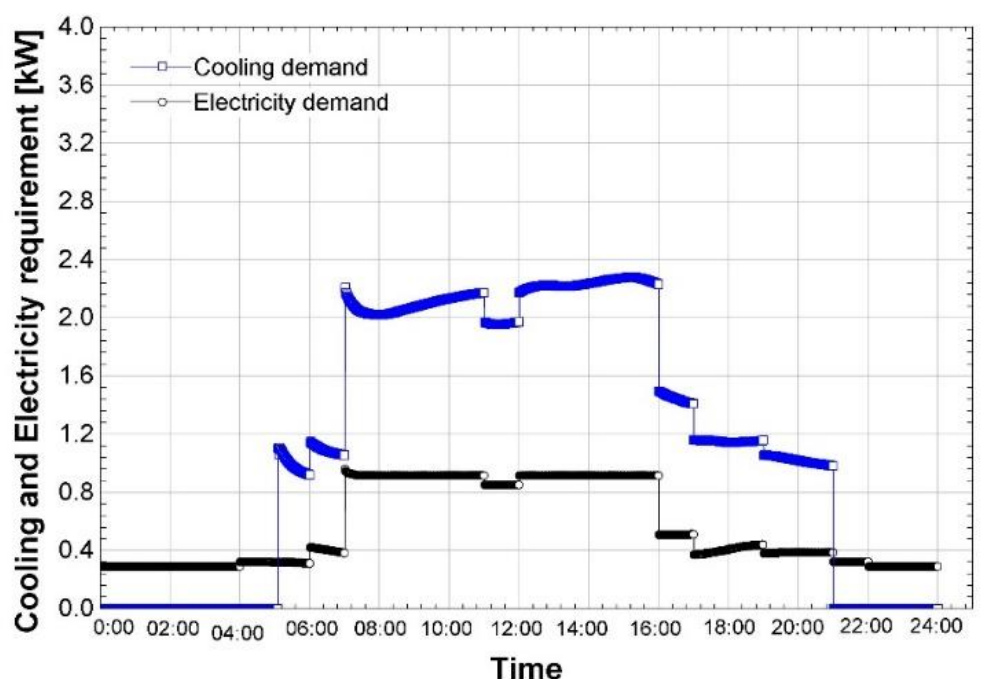

Fig.2. Cooling and electricity demand during a typical day for an assumed office room

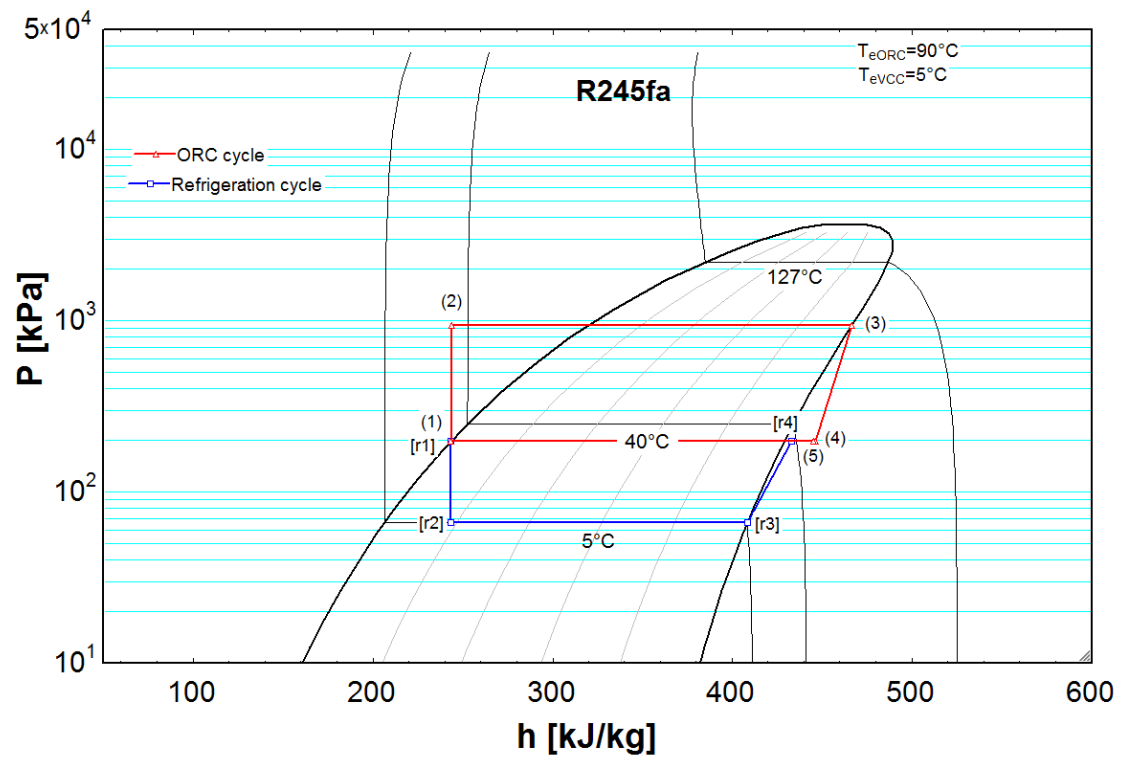




$$
\dot{Q}_{c o l}=\eta_{c o l} \cdot A_{c o l} \cdot G=\dot{m}_{c w} \cdot c_{p, c w} \cdot\left(T_{c o l}-T_{s t 10}\right)
$$

202

203

204

205

206

207

208

209

210

211

212

213

$$
M_{s t 1} \cdot c_{p, w} \cdot \frac{\partial T_{s t 1}}{\partial t}=\dot{m}_{c w} \cdot c_{p, c w} \cdot\left(T_{c o l}-T_{s t, 1}\right)+\dot{m}_{w} \cdot c_{p, w} \cdot\left(T_{s t, 2}-T_{s t, 1}\right)-U_{t} \cdot A_{s t 1} \cdot\left(T_{s t, 1}-T_{a m}\right)
$$

214

$$
\begin{aligned}
M_{s t, i} \cdot c_{p, w} \cdot \frac{\partial T_{s t, i}}{\partial t} & =\dot{m}_{c w} \cdot c_{p, c w} \cdot\left(T_{s t, i-1}-T_{s t, i}\right)+\dot{m}_{w} \cdot c_{p, w} \cdot\left(T_{s t, i+1}-T_{s t, i}\right)-U_{t} \cdot A_{s t, i} \\
\cdot & \left(T_{s t, i}-T_{a m}\right)
\end{aligned}
$$

\subsection{Heat storage}

A pressurised water tank is adopted as the heat storage unit. Its volume determines the energy storage capacity and also the effect of its temperature levels on the performance. The water tank is modelled in transient states by considering the thermocline behaviour. It is analysed using a one-dimensional temperature distribution model [28]. Isothermal mixing zone methodology is used for simulations; this multi node simulation allows the system to show potential temperature gradient inside the tank. The cylinder volume has been divided into 10 equal layers. In every control volume, an energy balance equation can be written considering the heat loss to the environment [6], [29]. By solving all the energy balance equations simultaneously, the temperature distribution inside the tank can be determined. Eq.(3) is the energy balance in the first control volume, Eq.(4) is the energy balance in the internal volumes 'i'. Eq.(5) is the energy balance in the last control volume. 


$$
\begin{aligned}
M_{s t, N} \cdot c_{p} \cdot \frac{\partial T_{s t, N}}{\partial t} & =\dot{m}_{c w} \cdot c_{p} \cdot\left(T_{s t, N-1}-T_{s t, N}\right)+\dot{m}_{d r a w n} \cdot c_{p} \cdot\left(T_{w o}-T_{s t, N}\right)-U_{t} \cdot A_{s t, N} \\
& \cdot\left(T_{s t, N}-T_{a m}\right)
\end{aligned}
$$

\subsection{Expander}

In the present study, a decision was made to use a scroll type expander as this is particularly welladapted to small-scale Rankine cycle applications. A semi empirical model was adapted from the study, based on Lemort et al. [30]. Guiffarida [31] further improved the model for use with all refrigerant. This expander model was implemented to analyse the variation of the expander performance over the changing conditions. modelling is following same steps with reference, such as 1) adiabatic pressure supply, 2) Isobaric supply cooling down, 3) internal leakage, 4) adiabatic and reversible expansion to the adapted pressure 5) adiabatic expansion at constant machine volume, 6) adiabatic fluid mixing 7) isobaric exhaust heating-up or cooling down. All detailed calculation procedures are not explained here but some important parts are given. Mass flow rate of the refrigerant is determined from Eq.(6)

$$
\dot{m}_{r}=\rho_{s u 1} \cdot A_{s u} \cdot \sqrt{2 \cdot\left(h_{s u}-h_{s u 1}\right)}
$$

$\dot{m}_{r}$ is refrigerant mass flow rate at the inlet port in the scroll expander. This mass flow rate includes leakage flows as well. After isobaric cooling down the refrigerant, leakage flow rate can be determined by Eq.(7) and Eq.(8):

$$
\begin{gathered}
\dot{m}_{r}=\rho_{s u, 2} \cdot V_{s w} \cdot \frac{N}{60}+\dot{m}_{\text {leak }} \\
\dot{m}_{\text {leak }}=\rho_{\text {leak }} \cdot A_{\text {leak }} \cdot \sqrt{2 \cdot\left(h_{s u, 2}-h_{\text {leak }}\right)}
\end{gathered}
$$

$V_{S W}$ and $\mathrm{N}$ indicate swept volume and rotation speed, respectively.

After leakage flow leaves from the main stream, rest of the working fluid expanded according to volumetric built in ratio. Then adiabatic expansion at constant volume occurs. Main stream refrigerant is mixed with leakage flow and finally exhaust heat transfer happens. After thermodynamic states are determined, internal expansion power can be found from Eq. (9):

$$
W_{\text {in }}=\left(\dot{m}_{r}-\dot{m}_{\text {leak }}\right) \cdot\left[\left(h_{s u, 2}-h_{a d}\right)-v_{a d} \cdot\left(P_{a d}-P_{e x, 2}\right)\right]
$$

Shaft power can be find from Eq. (10):

$$
W_{\text {shaft }}=P_{\text {in }}-\frac{2 \cdot \pi \cdot N}{60} \cdot \tau_{\text {loss }}
$$


Fig. 4 shows the result of the model when the ambient temperature is held at $23{ }^{\circ} \mathrm{C}$ for refrigerant $\mathrm{R} 245 \mathrm{fa}$ but supply pressure is varied.

239

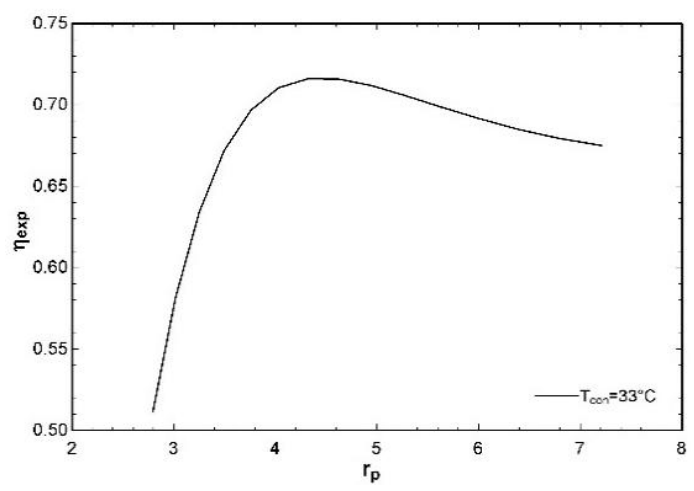

Fig.4. Variation of expander isentropic efficiency by pressure ratio

\subsection{Boiler}

In the proposed system, there are three heat exchangers but the boiler is the most important component of the ORC because boiler uses hot water from the water tank to evaporate the refrigerant. It is expected that the temperature of the water varies with time due to consumption and charging for this reason, a sliding pressure operation is implemented in the modelling, which means that the evaporation pressure is determined from the water inlet temperature. However, effect of water inlet temperature is the not only consideration. Since one of the target of this study is controlling the evaporation temperature by changing water mass flow rate, the boiler needs to be modeled to obtain the effect of the water mass flow rate. By neglecting the pressure losses and making the study more practical, double pipe heat exchangers were selected as a boiler in the ORC. To conduct the off-design analysis of the heat exchanger, the effectiveness-NTU method was implemented.

$$
N T U=\frac{U \cdot A}{C_{\min }}
$$

Where NTU is number of transfer units, $U$ is overall heat transfer coefficient. The boiler consists of two regions in one exchanger such as the single phase and evaporation regions as given in Fig.5. In off-design operation, the total length of the boiler is constant, however, regions may differ according to heat source conditions. Heat transfer coefficient can be determined as follows:

$$
h_{h}=\frac{N u \cdot k}{d}
$$


Here, $\mathrm{Nu}, \mathrm{k}$ and $\mathrm{d}$ are Nusselt number, thermal conductivity of refrigerant and diameter of the tube.

262 Since flow inside tube is turbulent, the Nusselt number of single phase region for liquid water and 263 pure liquid R245fa can be found with Gnielinski [32] equation:

$$
N u=\frac{\left(\frac{f}{8}\right)(R e-1000) \operatorname{Pr}}{1+12.7\left(\frac{f}{8}\right)^{0.2}\left(\operatorname{Pr}^{2 / 3}-1\right)}
$$

264

265

where $\mathrm{f}$ can be calculated with Petukhov [33] equation:

$$
f=(0.79 \ln R e-1.64)^{-2}
$$

267 When boiling of the refrigerant R245fa takes place, fluid is in a two-phase state (saturated mixture). 268 For boiling in the evaporator, the Kenning-Cooper correlation is used as given by Sun and Mishima 269 [34] based on their findings.

$$
N u_{b}=\left[1+1.8 X^{-0.87}\right] 0.023 \operatorname{Re}_{l}^{0.8} \operatorname{Pr}_{l}^{0.48}
$$

where $\mathrm{X}$ is the Martinelli factor which is given from vapour quality $\mathrm{x}$ :

$$
X=\left(\frac{1-x}{x}\right)^{0.9}\left(\frac{\rho_{v}}{\rho_{l}}\right)^{0.5}\left(\frac{\mu_{l}}{\mu_{v}}\right)^{0.1}
$$

272

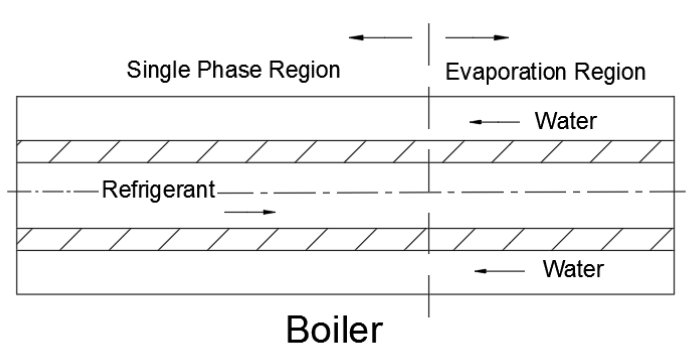

Fig.5. Schematic of boiler single and two-phase regions boundary

\subsection{Compressor}

An important parameter of the VCC unit is compressor work. The compressor is directly coupled with the expander, so the compressor work equation can be included with mechanical transmission efficiency. The equation is given as: 


$$
\dot{W}_{\text {comp }}=\frac{\dot{m}_{r c} \cdot\left(h_{r 4}-h_{r 3}\right)}{\eta_{m e c} \cdot \eta_{i}}
$$

279 Here, $\eta_{\text {mec }}$ and $\eta_{i}$ are mechanical and isentropic efficiency of the compressor, respectively. $\eta_{\text {mec }}$ 280 changes between $0.95-1$ and it can be assumed as 0.95 [18]. However, $\eta_{i}$ changes with condensation and evaporation pressure ratio. So, the following equation is used [35].

$$
\eta_{i}=0.874-0.0135 \cdot \frac{P_{\text {con }}}{P_{\text {eva }}}
$$

282

where $\mathrm{P}_{\text {con }}$ and $\mathrm{P}_{\mathrm{eva}}$ are condensation and evaporation pressures.

\subsection{Evaporator}

As previously mentioned, in cooling mode, evaporation temperature is kept constant, the refrigerant mass flow rate varies according to cooling requirements and this affects compressor work under different ambient conditions. In the calculations, cooling load is known parameter and taken from EnergyPlus data. Since evaporator inlet and outlet conditions are determined primarily, the mass flow rate of the refrigerant in cooling cycle can be found.

$$
\dot{Q}_{\text {cooling }}=\dot{m}_{r c} \cdot\left(h_{r 3}-h_{r 2}\right)
$$

\section{Results and discussions}

In order to evaluate the system performance, design conditions need to be determined first. These are determination of the design evaporation and condensation temperatures and later, the boiler is dimensioned as operation of the ORC depends on boiler performance. Transient mathematical model has been built in Matlab environment and results have been presented by using EES (Engineering Equation Solver) software. When design conditions are determined, the simulation is run, and collector and storage dimensions are changed until the system output matches with the desired output. The calculation procedure is briefly summarized in Fig.6. Useful solar heat is collected by the EFP collectors. This useful heat and collector water inlet temperature effects the output temperature which is mixed with the first element of the tank. Tank model gives temperature distribution of the water in tank. It is effected by two circulation waters one to the collector side and the other to the boiler side. Boiler model determines the evaporation temperature of the working fluid and also effects on tank temperature gradient as well. Expander model calculates the mass flow rate and shaft power output. The solar ORC and VCC systems are evaluated as separate systems except their condensing parts because VCC performance mainly depends on compressor electricity consumption and it can be 
calculated from the cooling load which is variable. Calculated mass flow rate from the evaporator is used to obtain compressor work. The compressor work is taken from the expander shaft and the rest of the energy is transmitted to the generator to generate electricity.

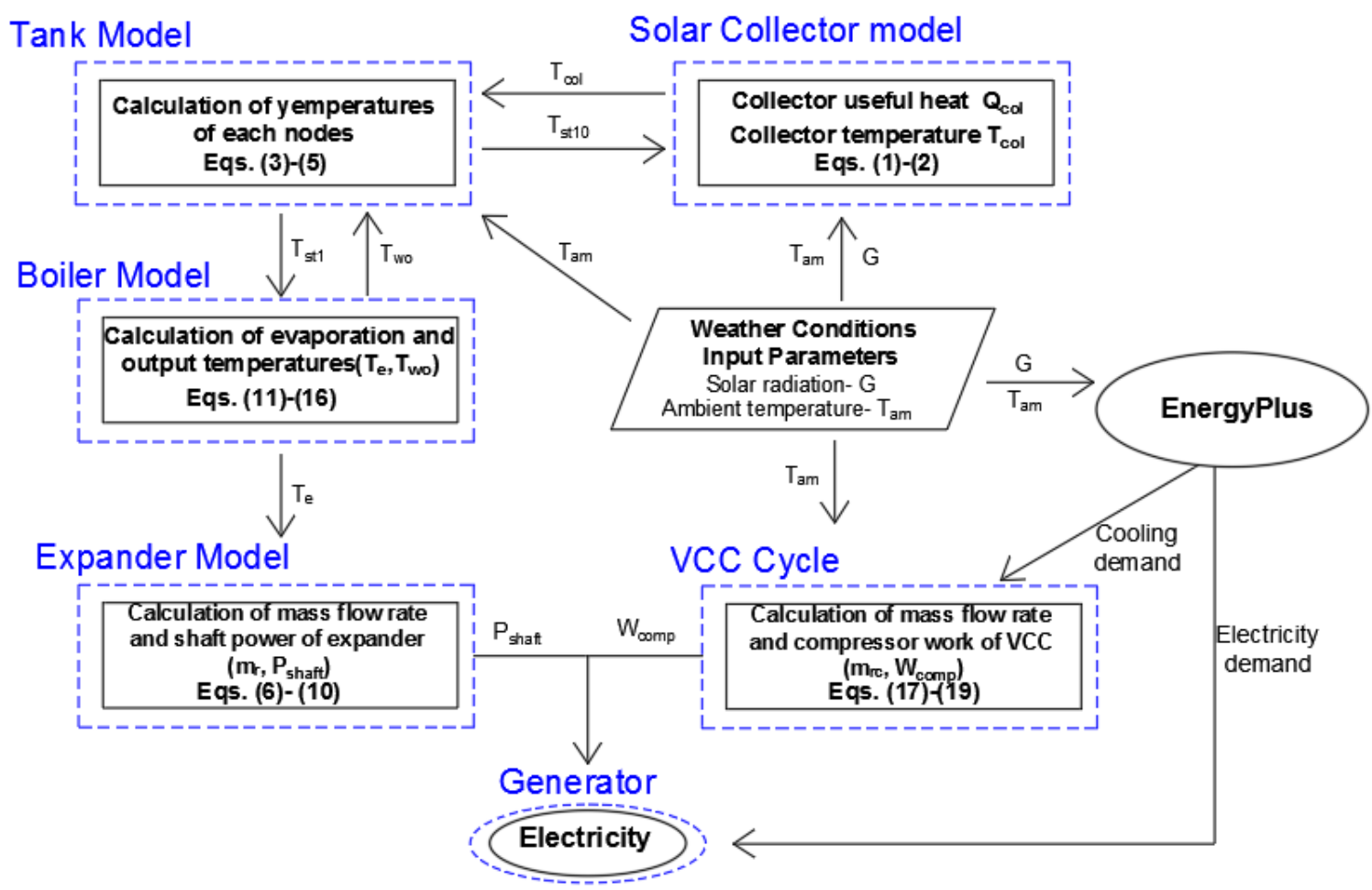

Fig.6. Calculation procedure of the system

\subsection{Determining of Design Conditions}

314 Condensing temperature of the ORC can be determined first, as it depends on the ambient temperature for air cooled condensers. Fig.7 shows ambient air temperature and solar irradiance variation during a warm day in July in Istanbul. Since the water tank is a finite heat storage, it is necessary to choose matched requirements to avoid over usage of the contained heat. Thus, before selecting the design conditions and parameters, the total electricity demand of the room is required. Variation of compressor work and total demands including electrical appliances as given in Fig.8. The compressor work was calculated according to the cooling load given in Fig.2. It is found that the maximum compressor work and total demand are $0.4 \mathrm{~kW}$ and $1.35 \mathrm{~kW}$, respectively. 


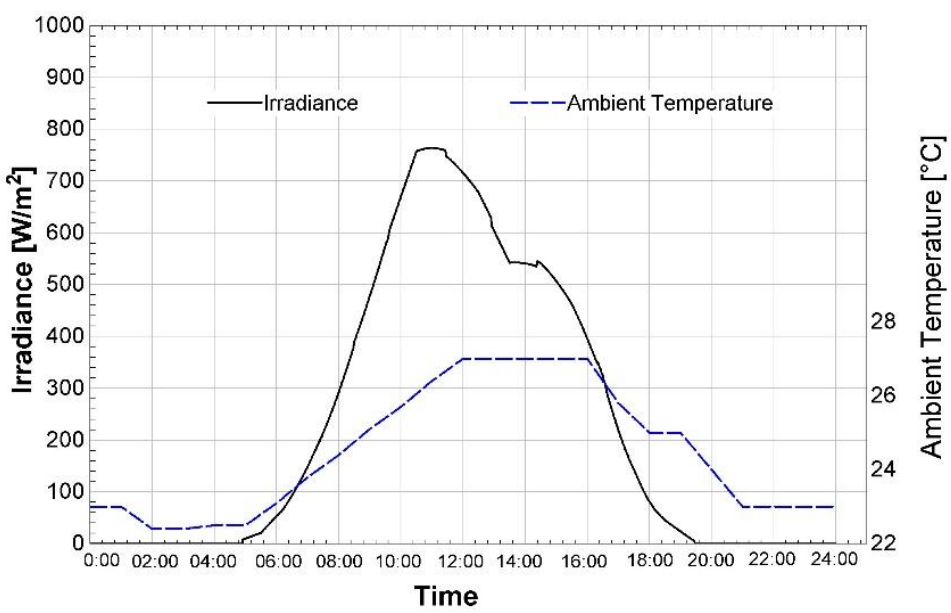

Fig.7. Weather data for a typical warm day in Istanbul

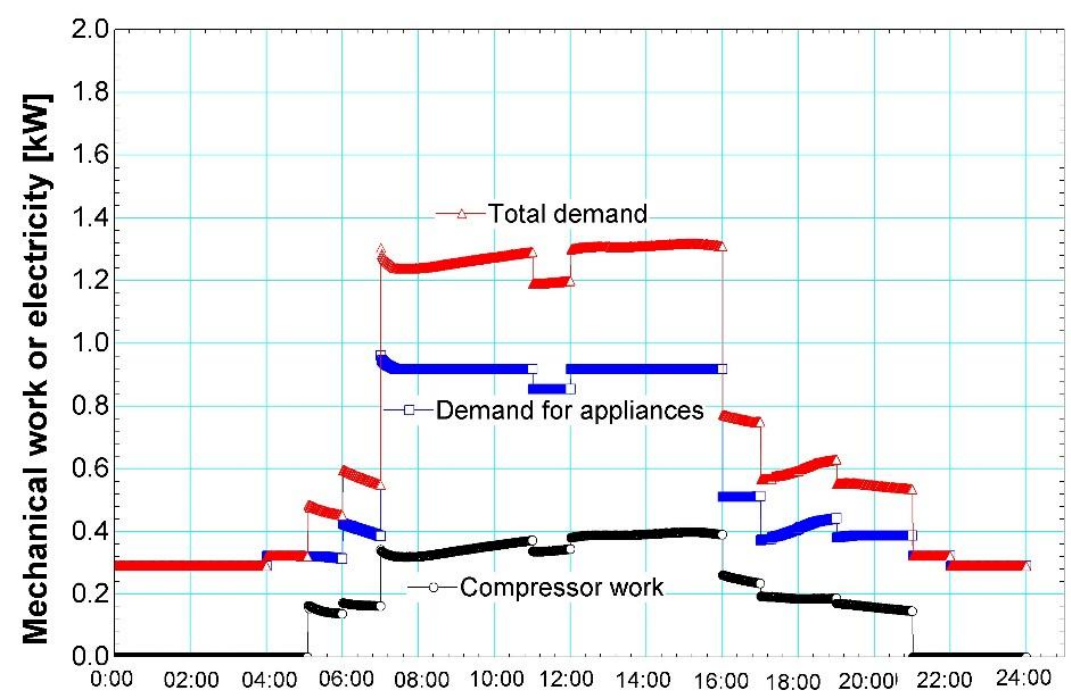

Time

Fig.8. Mechanical work or electricity demand of the system over time

To provide $1.35 \mathrm{~kW}$ of work from the expander shaft, the design evaporation temperature is selected as $95^{\circ} \mathrm{C}$ when considering the generator efficiency and safety factor. A volume of $150 \mathrm{~L}$ hot water tank is the standard household size in practice. However, in this study, charging and discharging heat levels are elevated compared to the conventional domestic water tanks. To maintain the required amount of heat to the system, the heat storage tank can be selected from $1.5 \mathrm{~m}^{3}$ to $9 \mathrm{~m}^{3}$. To provide useful solar heat for running the system at given design conditions, a $60 \mathrm{~m}^{2}$ collector area was chosen preliminarily, to be the same as the floor area of the simulated office room. In Table.2, design conditions for the ORC unit are summarised. 
Table 2. Selected design conditions and system specifications

\begin{tabular}{|c|c|c|c|c|c|}
\hline Parameter & Value & Parameter & Value & Parameter & Value \\
\hline Collector area & $60 \mathrm{~m}^{2}$ & $\begin{array}{c}\text { Evaporation } \\
\text { temperature in boiler }\end{array}$ & $95^{\circ} \mathrm{C}$ & $\begin{array}{c}\text { Boiler water side } \\
\text { diameter }\end{array}$ & $0.016 \mathrm{~m}$ \\
\hline Collector flow rate & $0.02 \mathrm{~kg} / \mathrm{s}$ & $\begin{array}{c}\text { Water inlet } \\
\text { Temperature }\end{array}$ & $105^{\circ} \mathrm{C}$ & $\begin{array}{c}\text { Boiler refrigerant side } \\
\text { diameter }\end{array}$ & $0.007 \mathrm{~m}$ \\
\hline Tank volume & $3.5 \mathrm{~m}^{3}$ & $\begin{array}{c}\text { Circulating water } \\
\text { flow rate }\end{array}$ & $0.3 \mathrm{~kg} / \mathrm{s}$ & Length of boiler & $21 \mathrm{~m}$ \\
\hline $\begin{array}{c}\text { Condensation } \\
\text { temperature }\end{array}$ & $36^{\circ} \mathrm{C}$ & \begin{tabular}{c} 
Heat from source: \\
\hline
\end{tabular} & $15.6 \mathrm{~kW}$ & Expander shaft output & $1.437 \mathrm{~kW}$ \\
\hline
\end{tabular}

338

\subsection{Off-design characteristics and control strategy}

Off-design performance of the system is based on the performance of the boiler given that work output is related to the evaporation temperature and this temperature is directly related to the source conditions which come from the water tank. Two parameters determine the evaporation temperature in the boiler. The first is source temperature; as solar energy is not constant during the day, the water tank is exposed to charge and discharge operations. In the day time, the tank is charged by the collected useful heat and its temperature is increased in spite of ORC runs at the same time. As a result of this increment, evaporating temperature and work output increase. The other parameter is mass flow rate of the water. The mass flow rate also has an influence on the evaporation temperature. The effects of the parameters are given in the Fig.9. This trend reveals the off-design operation of the system.

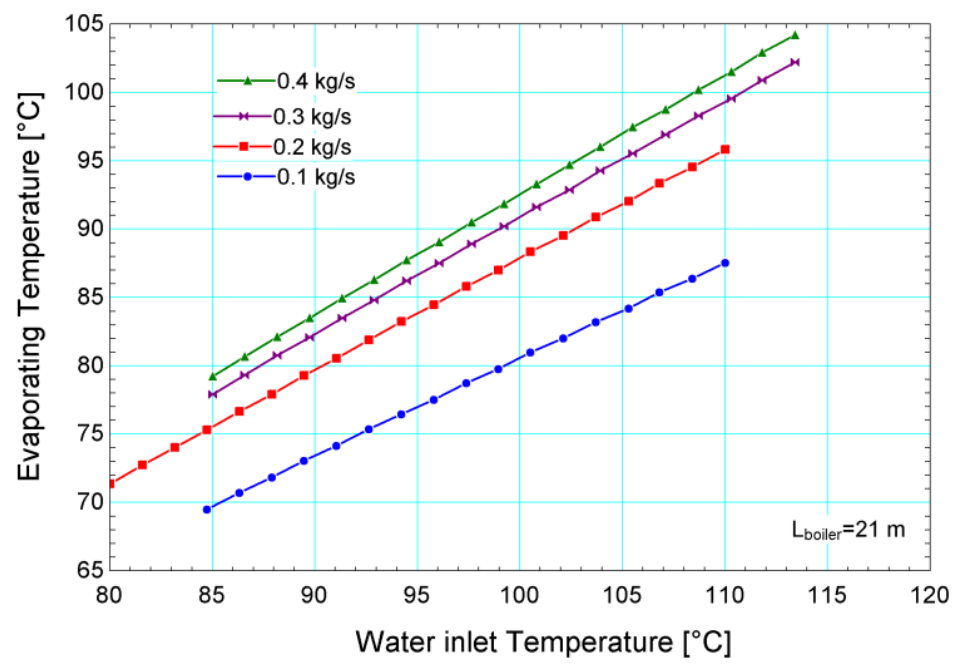

Fig.9. Evaporation temperature variation according to water inlet temperature and mass flow rates. 
Operation of the system is given as the basis: the ORC-VCC system operation starts at $06: 30$ to provide shaft work to the compressor; for cooling purposes, the collector pump operates and collected solar energy is accumulated in the storage, at the same time the ORC produces electricity for supplying to the electrical appliances. The water mass flow rate from tank to boiler is selected as 0.3 $\mathrm{kg} / \mathrm{s}$ to match with the demand via previously designed heat exchanger. The peak period ends at 16:00 and the other period which requires less work begins. In this period, the mass flow rate of water is reduced to $0.1 \mathrm{~kg} / \mathrm{s}$ to prevent excessive use of the heat source. This period is completed by 21:00 and energy in the tank is stored for the next day. There still exists an electricity requirement in the building, but this requirement can be met from the grid or a storage battery.

\subsection{Simulations}

To simulate the system, initial tank temperature selection is an important issue. As one-day simulation is carried out for a typical day, the temperature is not uniform in the tank due to the thermocline behaviour of the water. Normally, the initial temperatures of the water layers in the tank are the final temperatures of the previous day. However, this study considers only one day, thus, the initial temperatures need to be determined by iteration. Firstly, an assumed temperature value is given to all water layers and simulation is executed. The final temperatures of the first simulation are used as the initial temperatures of the next simulation. The steps were repeated until the end temperature distribution matches the initial temperature distribution [19]. It can be said that all of the useful solar energy charged to the tank is used for driving the ORC and the rest is transferred to the ambient as heat losses. The useful heat gain trend is directly affected by the solar irradiance pattern during the day. To observe the effect of the heat storage volume on the system performance, Fig.10 is plotted by using constant water mass flow rate during all periods.

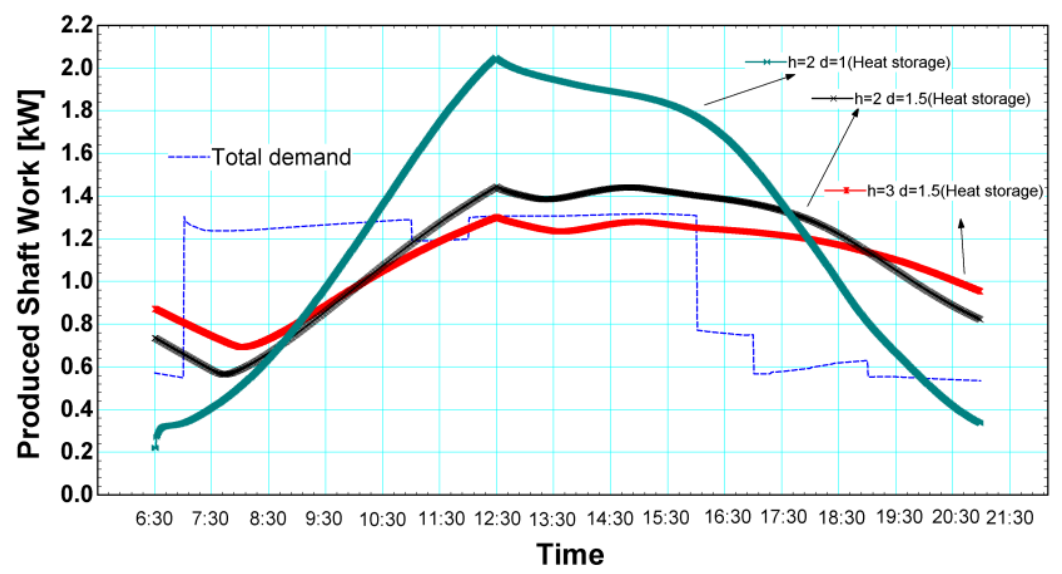

Fig.10. Produced shaft work versus time for various heat storage dimensions $\left(m_{w}=0.3 \mathrm{~kg} / \mathrm{s}\right.$, $\mathrm{A}_{\text {collector }}=60 \mathrm{~m}^{2}$ ) 
Since temperature increment is higher when using the constant solar collector area in smaller heat storages, peak output yields higher than the demand. A problem occurs, however, in the early morning period as output in this period cannot fulfil the demand. One solution is an increment to the storage capacity to avoid excessive temperature fall at night-time, however, using higher capacity storage decelerates the temperature increase at midday. As seen from Fig.10, when $3 \mathrm{~m}$ high and $1.5 \mathrm{~m}$ diameter heat storage units area used, produced work is getting closer to the demand but does not fulfil the midday demand as the temperature of the storage is not high enough.

Fig.11 shows expander efficiencies for using various storages. Since temperature alteration is high in small capacity storages, expander performance variation is considerable. For the bigger storages, expander performance can be further stabilised by avoiding excessive changes to the operating temperature.

In order to meet the electricity demand, the collector area is increased to $80 \mathrm{~m}^{2}$ and simulations have been conducted for two different storage sizes. Fig.12 shows that increments in collector and heat storage size are still not enough to meet the demand. As a solution, the mass flow rate of the water needs to be controlled for different periods, so power output and heat rejection rates can be controlled.

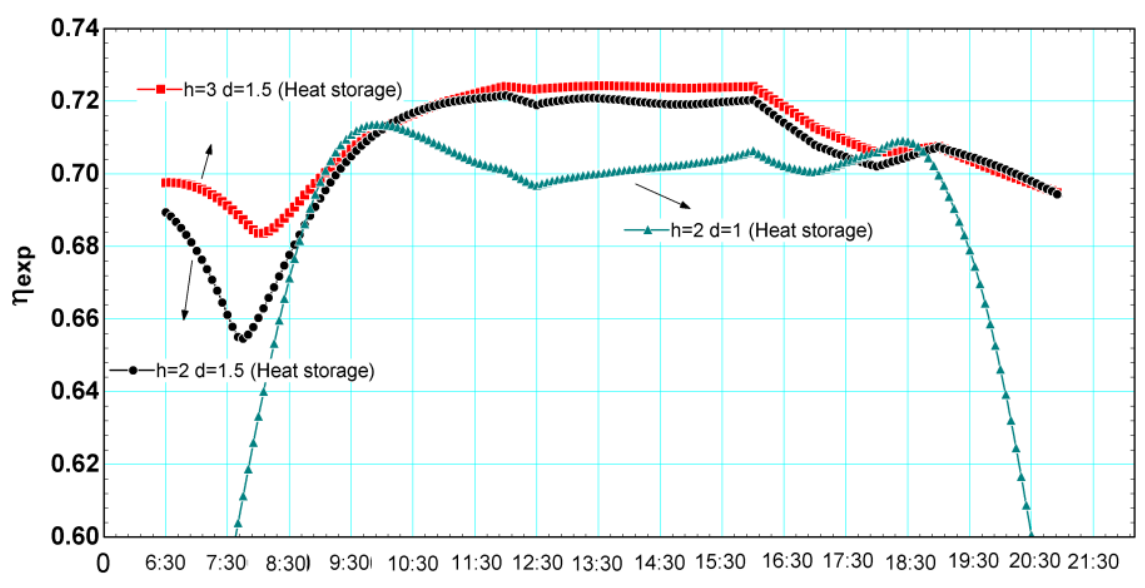

Time

Fig.11. Expander efficiency for various heat storage dimensions $\left(\mathrm{m}_{\mathrm{w}}=0.3 \mathrm{~kg} / \mathrm{s}, \mathrm{A}_{\text {collector }}=60 \mathrm{~m}^{2}\right)$ 


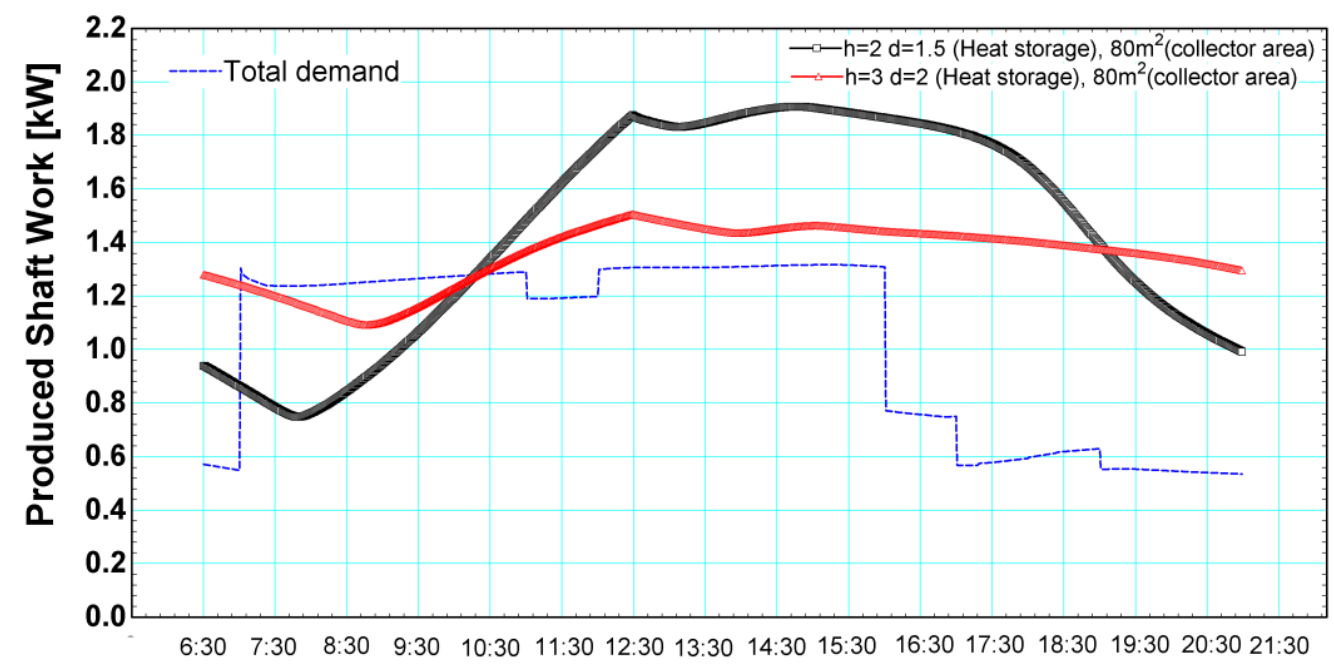

Time

403

404

405

406

407

408

409

410

411

412

413

414

415

416

Fig.12. Produced shaft work by time for various heat storage dimensions $\left(\mathrm{m}_{\mathrm{w} 2}=0.3 \mathrm{~kg} / \mathrm{s}\right.$,

$$
\mathrm{A}_{\text {collector }}=80 \mathrm{~m}^{2} \text { ) }
$$

In Fig.13, the mass flow rate is controlled for three different cases. Firstly, a case using a $60 \mathrm{~m}^{2}$ collector area and $2 \mathrm{~m}$ height with $1.5 \mathrm{~m}$ diameter storage tank has been analysed. Although performance is improved by controlling the mass flow rate, there is still a problem in the morning period, as the temperature of the tank at the end of the day does not satisfy the requirement in early morning, until the sufficient solar radiation is received. An increment to the storage capacity to avoid excessive temperature fall in the night period can be applied, however, it may require a larger collector area. To observe the phenomenon, a second case has been analysed. When the heat storage size is held constant and the collector area is increased to $80 \mathrm{~m}^{2}$, over production occurred at midday, however, the problem still exists in the early morning. As a final case, the storage size is also increased with the collector area. With these final changes, produced work fulfils the demand.

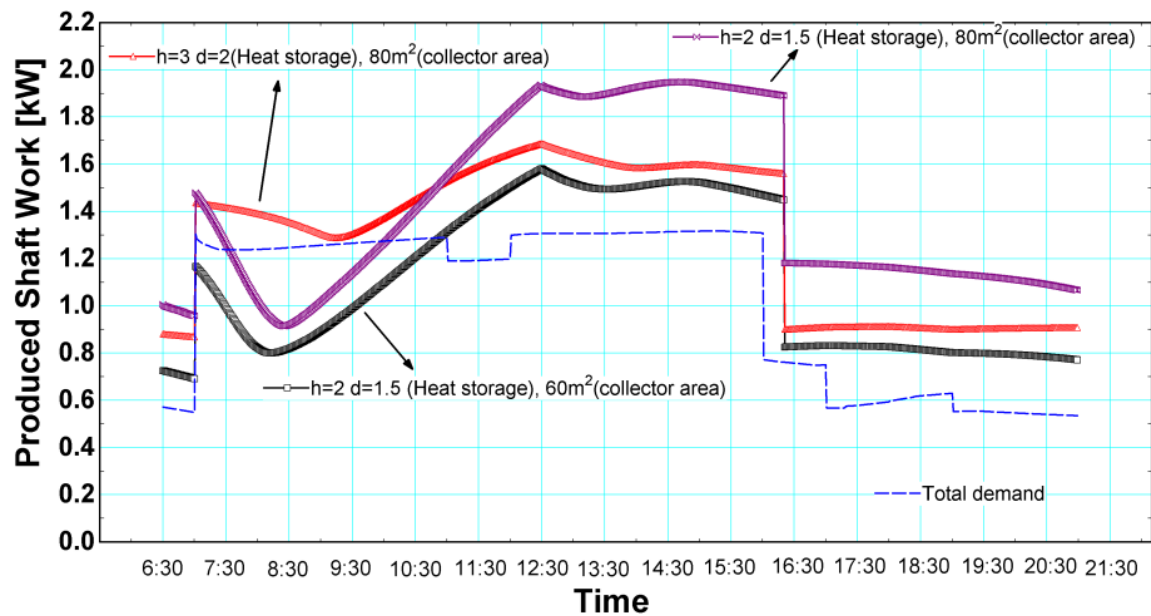

Fig.13. Produced shaft work by time with control strategy $\left(\mathrm{m}_{\mathrm{w} 1}=0.1 \mathrm{~kg} / \mathrm{s}, \mathrm{m}_{\mathrm{w} 2}=0.3 \mathrm{~kg} / \mathrm{s}\right)$ 
420 One of the advantages of the proposed system is that it should operate and show a good performance 421 in winter days without any modification by switching to CHP mode. In this mode, the compressor 422 does not run and the VCC indoor air unit evaporator operates as the ORC condenser, which is given in 423 Fig.1b. Since this heat exchanger located in the air conditioning cycle, what would normally be 424 wasted condensing heat can be used for heating purpose. The condensation temperature is adjusted at $42538^{\circ} \mathrm{C}$ to heat up the indoor unit blowing air. This temperature is identical to the condensing 426 temperature in ORC-cooling mode. More specifically, the ORC operation would not be affected by 427 the mode switch as a result of the same condensing temperature and pressure. However, electricity 428 output is expected to decrease, as solar heat would be lower than in the summer. Fig.14 shows weather condition for a sunny day in February. Solar radiation is quite good but ambient weather temperature is around $12{ }^{\circ} \mathrm{C}$ which shows heating is needed. Solar collectors and ORC work same as with the ORC-cooling mode but expander outlet is directed to the indoor heat exchanger. Fig.15 shows instant electricity generation by the ORC, the magnitude of the production looks not satisfying but electricity production in daily basis is $5.5 \mathrm{kWh}$. The reason is lower tank temperature. Since solar irradiance is not good in previous days, water tank temperature reduces and it causes lower evaporation temperature with lower electricity output. It should be noted that while electricity is produced its useful condensing heat, almost $7 \mathrm{~kW}$, can be used for space heating. Required heat is transferred to the indoor air and the rest is ejected by the outdoor condenser as seen in Fig.1b.

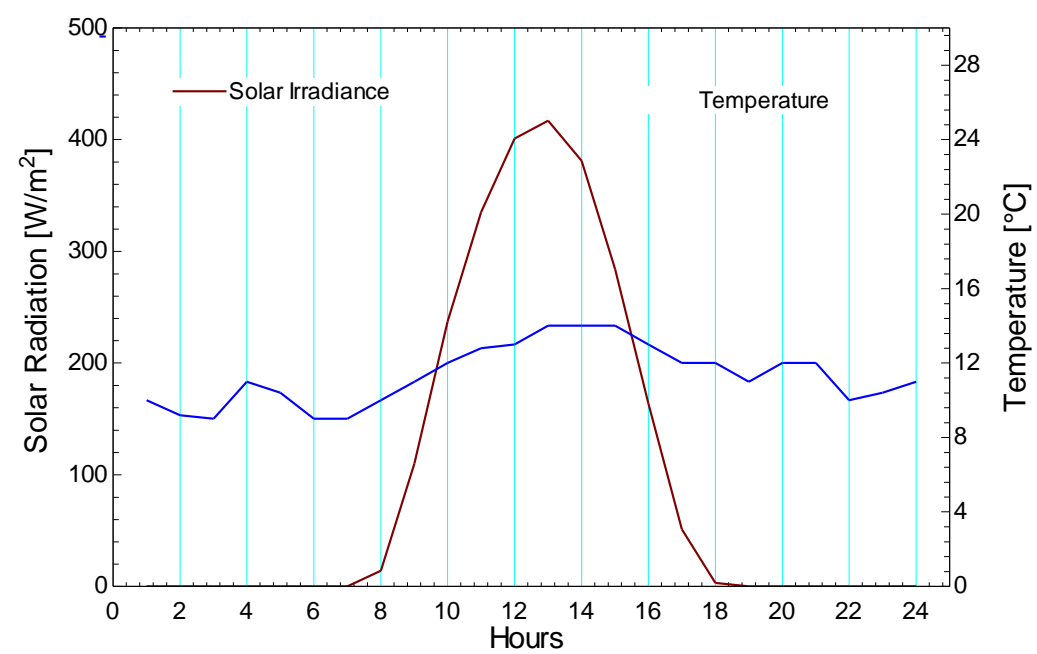

Fig.14. Solar radiation and ambient temperature profile on a sunny winter day 


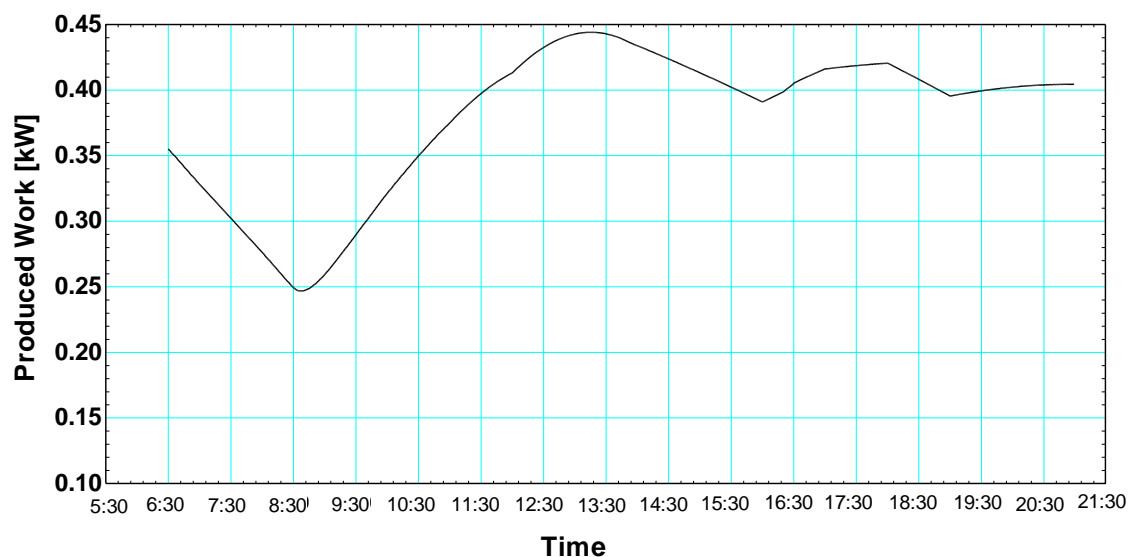

Fig.15. Produced shaft work in the heating mode of ORC-VCC

\section{Conclusion}

In this study, the modelling of the solar ORC-VCC system integrated with a sensible heat storage unit operating at off-design conditions has been presented. Electricity and cooling demand from the end user has been also considered from the point of view of control strategies. In the solar part, evacuated flat plate collectors have been used and collectors linked with a sensible heat storage unit. The heat storage unit has been modelled on the multi node analysis method to obtain thermocline phenomena. A transient analysis has been conducted to predict system outputs considering the off-design performance; in this way the analysis differs from the steady-state models. As working conditions have an influence on expander performance, electricity output is also effected. It is shown that water flow rate control strategies are promising and can improve the precision between the produced work and the demand. Sizes of the components have been determined according to summer conditions for Istanbul for ORC-cooling mode. It was found that to meet electricity and cooling demand for studied office, $80 \mathrm{~m}^{2}$ collector array and $9.4 \mathrm{~m}^{3}$ heat storage are required. Additionally, this system with selected components have been analysed for a winter day as ORC-heating mode and $5.5 \mathrm{kWh}$ electricity and $104 \mathrm{kWh}$ heating load potential has been obtained.

\section{ACKNOWLEDGEMENTS}

The authors would like to thank the European Commission for the Marie Curie Fellowship grant (H2020-MSCA-IF-2014-658217, H2020-MSCA-IF-2015-703746).

\section{REFERENCES}

[1] C. Li, J. Zhou, Y. Cao, J. Zhong, Y. Liu, C. Kang, Y. Tan, Interaction between urban microclimate and electric air-conditioning energy consumption during high temperature season, Appl. Energy. 117 (2014) 149-156. doi:10.1016/j.apenergy.2013.11.057. 
[2] P. Gang, L. Jing, J. Jie, Design and analysis of a novel low-temperature solar thermal electric system with two-stage collectors and heat storage units, Renew. Energy. 36 (2011) 2324-2333. doi:10.1016/j.renene.2011.02.008.

[3] M. Ciani Bassetti, D. Consoli, G. Manente, A. Lazzaretto, Design and off-design models of a hybrid geothermal-solar power plant enhanced by a thermal storage, Renew. Energy. 128 (2018) 460-472. doi:10.1016/j.renene.2017.05.078.

[4] Z. Li, F. Boyle, A. Reynolds, Domestic application of micro wind turbines in Ireland: Investigation of their economic viability, Renew. Energy. 41 (2012) 64-74. doi:10.1016/j.renene.2011.10.001.

[5] F.A. Al-Sulaiman, F. Hamdullahpur, I. Dincer, Performance assessment of a novel system using parabolic trough solar collectors for combined cooling, heating, and power production, Renew. Energy. 48 (2012) 161-172. doi:10.1016/j.renene.2012.04.034.

[6] E. Bellos, C. Tzivanidis, C. Symeou, K.A. Antonopoulos, Energetic, exergetic and financial evaluation of a solar driven absorption chiller - A dynamic approach, Energy Convers. Manag. 137 (2017) 34-48. doi:10.1016/j.enconman.2017.01.041.

[7] A. Lubis, J. Jeong, K. Saito, N. Giannetti, H. Yabase, M. Idrus Alhamid, Nasruddin, Solarassisted single-double-effect absorption chiller for use in Asian tropical climates, Renew. Energy. 99 (2016) 825-835. doi:10.1016/j.renene.2016.07.055.

[8] H. Wang, R. Peterson, T. Herron, Design study of configurations on system COP for a combined ORC (organic Rankine cycle) and VCC (vapor compression cycle), Energy. 36 (2011) 4809-4820. doi:10.1016/j.energy.2011.05.015.

[9] Y.R. Li, X.Q. Wang, X.P. Li, J.N. Wang, Performance analysis of a novel power/refrigerating combined-system driven by the low-grade waste heat using different refrigerants, Energy. 73 (2014) 543-553. doi:10.1016/j.energy.2014.06.054.

[10] H. Li, X. Bu, L. Wang, Z. Long, Y. Lian, Hydrocarbon working fluids for a Rankine cycle powered vapor compression refrigeration system using low-grade thermal energy, Energy Build. 65 (2013) 167-172. doi:10.1016/j.enbuild.2013.06.012.

[11] K. Hoon, H. Perez-blanco, Performance analysis of a combined organic Rankine cycle and vapor compression cycle for power and refrigeration cogeneration, Appl. Therm. Eng. 91 (2015) 964-974. doi:10.1016/j.applthermaleng.2015.04.062.

[12] F. Molés, J. Navarro-Esbrí, B. Peris, A. Mota-Babiloni, K. Kontomaris, Thermodynamic analysis of a combined organic Rankine cycle and vapor compression cycle system activated with low temperature heat sources using low GWP fluids, Appl. Therm. Eng. 87 (2015) 444 453. doi:10.1016/j.applthermaleng.2015.04.083.

[13] E. Cihan, B. Kavasogullari, Energy and Exergy Analysis of a Combined Refrigeration and Waste Heat Driven Organic Rankine Cycle System, Therm. Sci. (2015). doi:doi.org/10.2298/TSCI150324002C.

[14] M.T. Nasir, K.C. Kim, Working fluids selection and parametric optimization of an Organic Rankine Cycle coupled Vapor Compression Cycle (ORC-VCC) for air conditioning using low grade heat, Energy Build. 129 (2016) 378-395. doi:10.1016/j.enbuild.2016.07.068.

[15] B. Saleh, Parametric and working fluid analysis of a combined organic Rankine-vapor compression refrigeration system activated by low-grade thermal energy, J. Adv. Res. 7 (2016) 651-660. doi:10.1016/j.jare.2016.06.006.

[16] N. Zheng, J. Wei, L. Zhao, Analysis of a solar Rankine cycle powered refrigerator with zeotropic mixtures, Sol. Energy. 162 (2018) 57-66. doi:10.1016/j.solener.2018.01.011. 
[17] H. Wang, R. Peterson, K. Harada, E. Miller, R. Ingram-Goble, L. Fisher, J. Yih, C. Ward, Performance of a combined organic Rankine cycle and vapor compression cycle for heat activated cooling, Energy. 36 (2011) 447-458. doi:10.1016/j.energy.2010.10.020.

[18] A. Yilmaz, Transcritical organic Rankine vapor compression refrigeration system for intercity bus air-conditioning using engine exhaust heat, Energy. 82 (2015) 1047-1056. doi:10.1016/j.energy.2015.02.004.

[19] C. Kutlu, J. Li, Y. Su, G. Pei, S. Riffat, Off-design performance modelling of a solar organic Rankine cycle integrated with pressurized hot water storage unit for community level application, Energy Convers. Manag. 166 (2018) 132-145. doi:10.1016/j.enconman.2018.04.024.

[20] V. Lemort, S. Declaye, S. Quoilin, Experimental characterization of a hermetic scroll expander for use in a micro-scale Rankine cycle, Proc. Inst. Mech. Eng. Part A J. Power Energy. 226 (2012) 126-136. doi:10.1177/0957650911413840.

[21] D.B. Crawley, L.K. Lawrie, U.S. Army, C. Champaign, I. Curtis, O. Pedersen, F.C. Winkelmann, EnergyPlus: Energy Simulation Program, ASHRAE J. 42 (2000) 49-56. doi:10.1.1.122.6852.

[22] T. Yilmaz, M.T. Erdinç, Energetic and exergetic investigation of a novel refrigeration system utilizing ejector integrated subcooling using different refrigerants, Energy. 168 (2019) 712727. doi:10.1016/j.energy.2018.11.081.

[23] S. Unal, C. Kutlu, T. Erdinc, Performance improvement potentials of low global warming potential refrigerants for intercity bus air conditioning system, Therm. Sci. 22 (2018) 15151524. doi:https://doi.org/10.2298/TSCI160704084U.

[24] G.F. Hundy, Refrigeration, Air Conditioning and Heat Pumps, 5th ed., ButterworthHeinemann, 2016.

[25] J. Freeman, I. Guarracino, S.A. Kalogirou, C.N. Markides, A small-scale solar organic Rankine cycle combined heat and power system with integrated thermal-energy storage, Appl. Therm. Eng. 127 (2017) 1543-1554. doi:10.1016/j.applthermaleng.2017.07.163.

[26] J. Freeman, K. Hellgardt, C.N. Markides, Working fluid selection and electrical performance optimisation of a domestic solar-ORC combined heat and power system for year-round operation in the UK, Appl. Energy. 186 (2017) 291-303. doi:10.1016/j.apenergy.2016.04.041.

[27] F. Calise, M.D. D’Accadia, M. Vicidomini, M. Scarpellino, Design and simulation of a prototype of a small-scale solar CHP system based on evacuated flat-plate solar collectors and Organic Rankine Cycle, Energy Convers. Manag. 90 (2015) 347-363. doi:10.1016/j.enconman.2014.11.014.

[28] J.A. Duffie, W.A. Beckman, Solar Engineering of Thermal Processes, John Wiley, 2013.

[29] E. Bellos, M.G. Vrachopoulos, C. Tzivanidis, Energetic and exergetic investigation of a novel solar assisted mechanical compression refrigeration system, Energy Convers. Manag. 147 (2017) 1-18. doi:10.1016/j.enconman.2017.05.040.

[30] V. Lemort, S. Quoilin, C. Cuevas, J. Lebrun, Testing and modeling a scroll expander integrated into an Organic Rankine Cycle, Appl. Therm. Eng. 29 (2009) 3094-3102. doi:10.1016/j.applthermaleng.2009.04.013.

[31] A. Giuffrida, Modelling the performance of a scroll expander for small organic Rankine cycles when changing the working fluid, Appl. Therm. Eng. 70 (2014) 1040-1049. doi:10.1016/j.applthermaleng.2014.06.004.

[32] V. Gnielinsky, New equations for heat and mass transfer in turbulent pipe and channel flow, 
Int. Chem. Eng. 16 (1976) 359-368. doi:10.1016/j.cplett.2003.11.042.

[33] B.S. Petukhov, Heat Transfer and Friction in Turbulent Pipe Flow with Variable Physical Properties, Adv. Heat Transf. 6 (1970) 503-564. doi:10.1016/S0065-2717(08)70153-9.

[34] L. Sun, K. Mishima, An evaluation of prediction methods for saturated flow boiling heat transfer in mini-channels, Int. J. Heat Mass Transf. 52 (2009) 5323-5329. doi:10.1016/j.ijheatmasstransfer.2009.06.041.

[35] O. Brunin, M. Feidt, B. Hivet, Comparison of the working domains of some compression heat pumps and a compression-absorption heat pump, Int. J. Refrig. 20 (1997) 308-318.

564 doi:10.1016/S0140-7007(97)00025-X. 